\title{
Experiments for a Freshman Engineering Computing Course
}

\section{Dr. Charles H. Forsberg, Hofstra University}

Dr. Forsberg is a professor emeritus of Hofstra University in Hempstead, NY where he taught lecture and laboratory courses primarily in the thermal/fluids area of mechanical engineering. He is currently active in the Energy Engineering area. 


\title{
Experiments for a Freshman Engineering Computing Course
}

\begin{abstract}
The author teaches the Computer Programming for Engineers course at Hofstra University. This course is a required course for all engineering freshmen in all disciplines. We have a variety of students. Some are eager to learn and highly motivated. Others are much less enthusiastic. To make the course interesting and relevant, we use problems from science and engineering as much as possible. Special emphasis is given to choosing problems that are of general interest to all the students, regardless of engineering discipline. Through outcome assessments, we have found that students have particular difficulty with problems involving simultaneous equations and problems involving curve fitting; i. e., determining functions to model experimental data. The students especially have difficulty fitting data to power and exponential functions. However, surprisingly, they also have some difficulty with linear functions. We have added experiments to the computing course in an effort to enhance student motivation and understanding. The experiments have been specifically chosen to cover the difficult areas of the course. There is an electrical circuit experiment for the simultaneous equations topic, a fluid mechanics (i. e., orifice flow meter) experiment for curve fitting of power functions, and a heat transfer experiment (i. e., cooling of a metal cube) for curve fitting of exponential functions. There is also an experiment involving a cantilever beam. Loading weights at the end of the beam illustrates curve fitting of a linear function, and vibration of the beam illustrates the solution of a single implicit function to determine the various modes of vibration. The paper includes a detailed description of the experiments. It also includes the results of a student survey. The addition of experiments has been very well-received by the students. It has enhanced the dynamics of class sessions through increased student participation, and it is believed that the use of experiments has resulted in a very positive impact on student motivation. The author believes that the use of experiments has improved the students' understanding of the course material. However, due to lack of a control group, this belief cannot be confirmed by the current study.
\end{abstract}

\section{Introduction}

The author teaches the Computer Programming for Engineers course, which is a required course for all engineering freshmen in all disciplines at Hofstra University. The course is about 2/3 Matlab and 1/3 Excel. We have a variety of students. Some are eager to learn and highly motivated. Others are much less enthusiastic. To make the course interesting and relevant, we use problems from science and engineering as much as possible. The problems are specifically chosen to illustrate the various topics covered in the computing course and to show the usefulness of the computer in their solution. Special emphasis is given to choosing problems that are of general interest to all the students, regardless of engineering discipline. Students need to be familiar with algebra, trigonometry, and very basic concepts of integral calculus. It has been observed that some students are deficient in one or more of these areas.

Through outcome assessments, we have found that students have particular difficulty with problems involving simultaneous equations and problems involving curve fitting; i. e., determining functions to model experimental data. The course limits these functions to 
polynomial, power, and exponential functions. The students especially have difficulty fitting data to power and exponential functions. However, surprisingly, they also have some difficulty with linear functions.

We have added experiments to the computing course in an effort to enhance student motivation and understanding. The literature contains some information about this having been done for lecture classes in other curricular areas ${ }^{1-3}$. However, there is little in the literature about the addition of experiments to freshman engineering computer courses.

The experiments have been specifically chosen to cover the difficult areas of the course. There is an electrical circuit experiment for the simultaneous equations topic, a fluid mechanics (i. e., orifice flow meter) experiment for curve fitting of power functions, and a heat transfer experiment (i. e., cooling of a small metal cylinder) for curve fitting of exponential functions. There is also an experiment involving a cantilever beam. Loading weights at the end of the beam illustrates curve fitting of a linear function, and vibration of the beam illustrates the solution of a non-linear equation with one unknown to determine the frequencies of the various modes of vibration.

This paper includes a detailed description of the experiments. It also includes the results of a student survey on the experiments' impact on student motivation and understanding.

The Experiments

As noted above, the experiments were chosen to illustrate the more-difficult portions of the course. Students enjoy participating in the performance of the experiments and the gathering of data. Unfortunately, sometimes student involvement in all the experiments is not possible due to large class size or lack of time. In these instances, the instructor demonstrates the experiments and provides the students with data taken previously. The students use the data in their function discovery and curve fitting. After this is done, the instructor compares the results with the theoretical predictions. For example, flow rate versus pressure drop is a power function for the orifice flow meter and the cooling of the metal cylinder by convection follows an exponential function. The individual experiments are now discussed in detail.

\section{Electric Circuit Experiment}

An experiment to illustrate simultaneous linear equations was built for an electric circuit problem from Gilat's excellent Matlab textbook ${ }^{4}$. The circuit consists of two power sources and five resistors. The students derive four simultaneous equations for the currents in the four loops of the circuit. This is done using the mesh current method based on Kirchhoff's voltage law. After the currents in the loops are determined by solving the simultaneous equations, the results are used to calculate the currents flowing through the five resistors. 
The circuit and the experiment are shown in Figures 1 and 2, respectively.

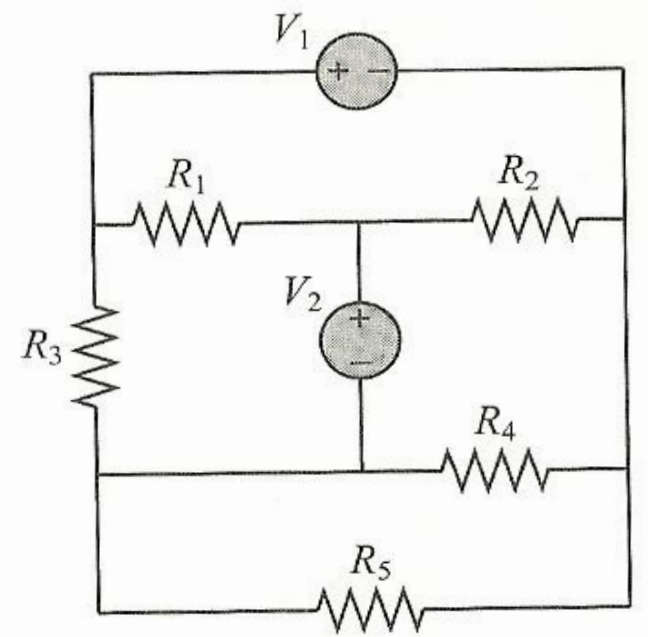

Figure No. 1 - The Electric Circuit (from Gilat ${ }^{4}$ )

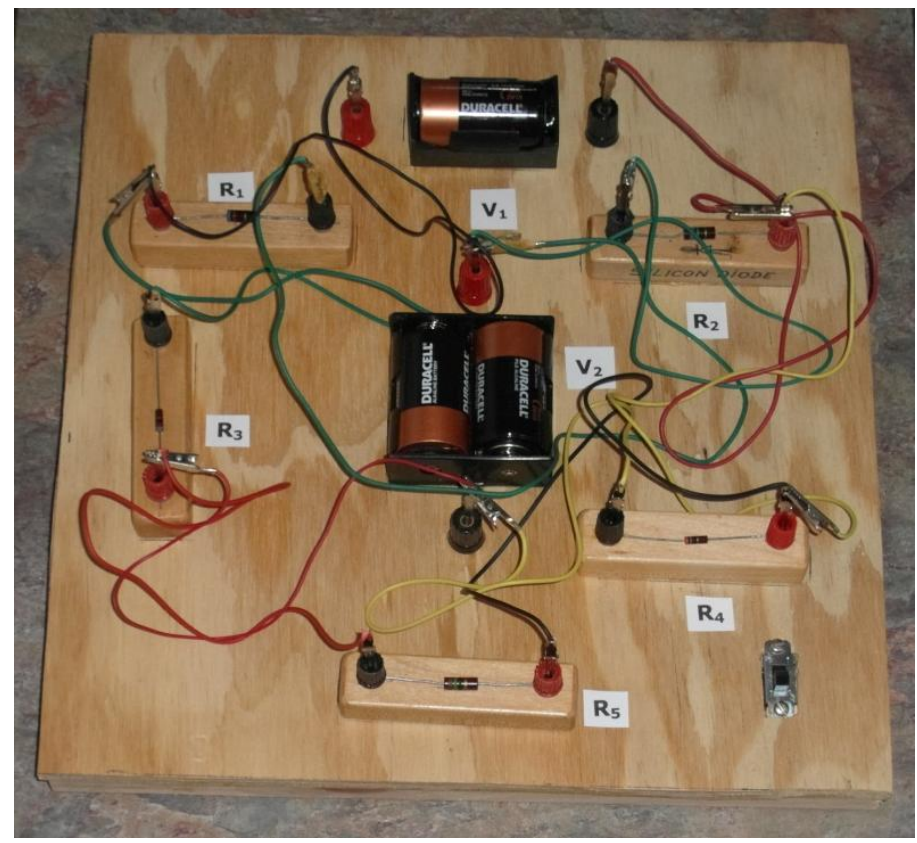


Figure No. 2 - The Electric Circuit Experiment

The experiment uses $\mathrm{D}$ batteries for the power sources (one battery for $\mathrm{V}_{1}$ and two batteries for $\mathrm{V}_{2}$ ). Carbon resistors are used for the five resistors. A dpst slide switch was used as an on-off switch for the batteries, and the experiment was mounted on a plywood box. Wires with alligator clips were used to connect the components. Measurements of the power source voltages, the resistances, and the electric currents flowing through the resistors were made with a digital multimeter ${ }^{5}$.

Measurements $\quad \mathrm{V}_{1}=1.57 \mathrm{~V}, \mathrm{~V}_{2}=3.07 \mathrm{~V}$

$$
\mathrm{R}_{1}=66.7 \Omega, \mathrm{R}_{2}=78.7 \Omega, \mathrm{R}_{3}=64.6 \Omega, \mathrm{R}_{4}=40.2 \Omega, \mathrm{R}_{5}=20.0 \Omega
$$

$\begin{array}{cccccc}\text { Currents through the Resistors }(\mathrm{mA}) & & \text { Calculated } & & \text { Measured } & \text { \% Difference } \\ & \mathrm{R}_{1} & 17.8 & & 14.8 & 20.3 \\ \mathrm{R}_{2} & 35.0 & 34.6 & 1.2 \\ \mathrm{R}_{3} & 29.2 & 28.4 & 2.8 \\ \mathrm{R}_{4} & 7.8 & 6.5 & 20.0 \\ \mathrm{R}_{5} & 15.8 & 18.0 & 12.2\end{array}$

Orifice Flow Meter

An orifice flow meter ${ }^{6}$ is calibrated in the fluid mechanics laboratory course. It was decided that this would be an excellent experiment to use in the Matlab course to illustrate data which follows a power relationship. The experiment is shown in Figure No. 3.

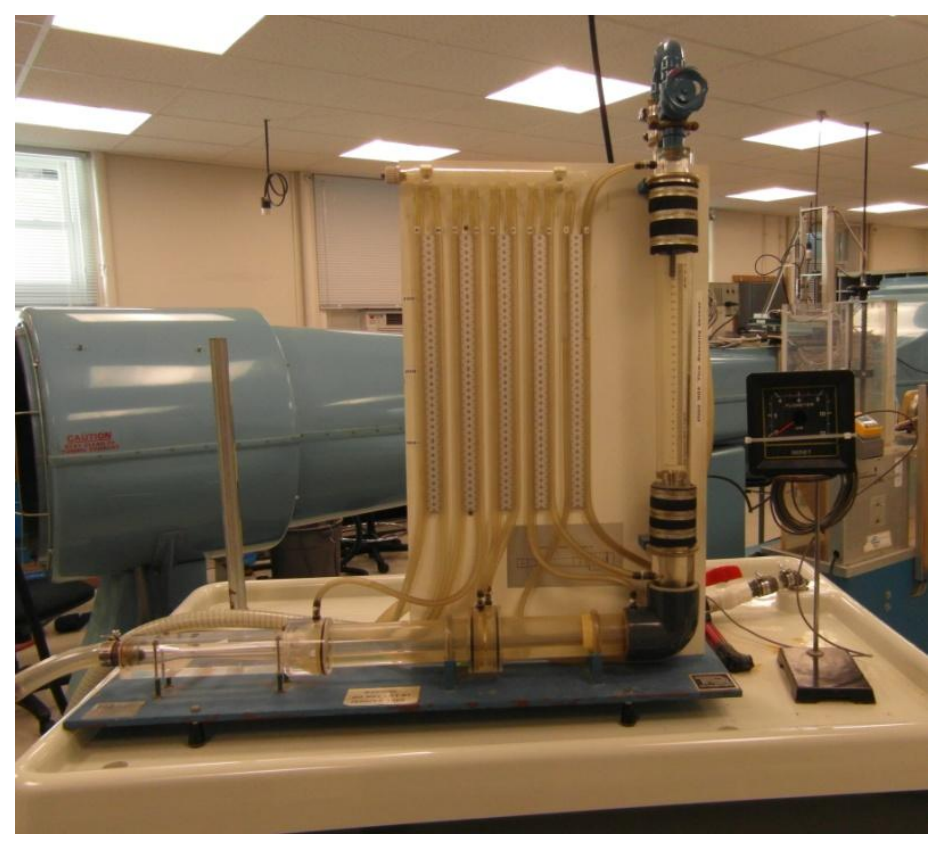




\section{Figure No. 3 - Orifice Flow Meter Experiment}

Water flows through the flow meter at a known flow rate which is measured by an analog flow meter. The flow meter has a center plate with a hole in it that is smaller than the general flow piping. This obstruction causes a pressure drop across the plate. The pressures on both sides of the orifice plate are measured by water tube manometers. The difference in pressures is proportional to the difference in height of the water in the manometer tubes on the two sides of the flow meter. Higher flow rates cause larger pressure drops across the orifice plate, as observed by larger differences in the water levels in the two manometer tubes.

Students visit the fluids laboratory and observe the operation of the orifice flow meter experiment. If the student group is small enough, the students participate in the experimentation and data collection. If not, the instructor explains and demonstrates the equipment. The students then return to the computer laboratory and the data is analyzed. The flow rate versus pressure drop data is plotted, using Matlab, on different types of axes to see whether it plots as a straight line. It is plotted on three sets of axes: two linear axes, two logarithmic axes, and one linear \& one logarithmic axis. It is found that the data approximates a straight line if both axes are logarithmic. This is characteristic of a power relationship. Having determined this, the students then use Matlab (and the polyfit function) to determine the functional relationship between the flow rate and pressure drop. Finally, the students plot the data and the function on log-log axes. They see that there is good correlation between the data and the function, the function plots as a straight line, and the data approximates a straight line. This reinforces the students' understanding that a power function plots as a straight line on log-log axes.

The following data was obtained from the experiment:

\begin{tabular}{|c|c|}
\hline Flow Rate Q (gpm) & $\left.\underline{\text { Pressure Difference } \mathrm{P}(\mathrm{mm} \mathrm{H}} \underline{\mathrm{m}}_{2} \underline{\mathrm{O}}\right)$ \\
\hline 1.25 & 11 \\
\hline 1.8 & 26 \\
\hline 2.1 & 31 \\
\hline 2.5 & 40 \\
\hline 2.9 & 50 \\
\hline 3.4 & 75 \\
\hline 4.0 & 90 \\
\hline 4.4 & 113 \\
\hline 5.0 & 135 \\
\hline 5.7 & 163 \\
\hline
\end{tabular}

The power relationship for this data obtained via Matlab and the polyfit function is 


$$
Q=0.3018 P^{0.5706}
$$

A plot of the data and the function on log-log axes is shown in Figure 4. The good correlation between the function and the data is clear. The straight-line characteristic is also observed.

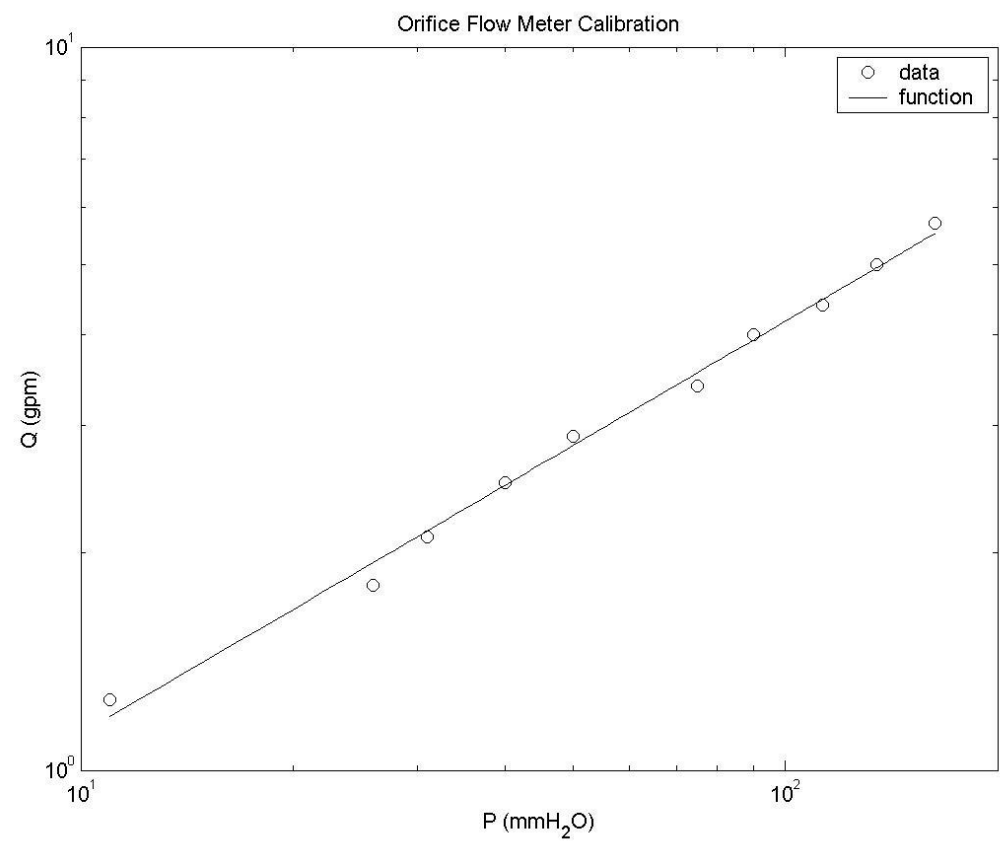

Figure No. 4 - Orifice Flow Meter Calibration

\section{Cooling of a Metal Cylinder Experiment}

This experiment is similar to the orifice flow meter experiment in that the students analyze the data to determine the appropriate function which fits the data. The specimen is an aluminum cylinder of 1/2-inch diameter and 1/2-inch length. A 1/16-inch hole is drilled in one end of the cylinder to about the center of the cylinder. A type-K thermocouple is inserted in the hole and the thermocouple is glued in place by Gorilla Glue. Care is taken during insertion of the thermocouple that the thermocouple bead contacts the cylinder and that no glue gets on the bead. Performance of the experiment is as follows: The cylinder is initially in a beaker of hot water. It is moved quickly to a beaker of cold water and the time-temperature response of the cylinder is observed. The temperature is measured by a thermocouple thermometer ${ }^{7}$. The response is slow enough that a stopwatch or wrist watch can be used for time measurement.

The aluminum cylinder is shown in Figure No. 5. In the left of the figure is the plug for connection of the thermocouple to the thermocouple thermometer. 


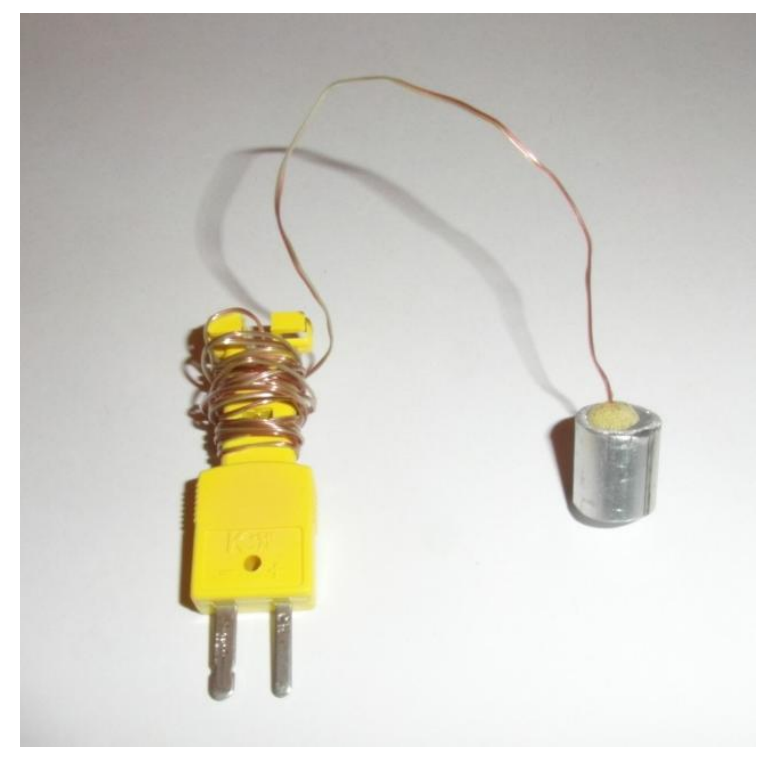

Figure No. 5 - Aluminum Cylinder for the Cooling Experiment

Heat transfer theory ${ }^{8}$ predicts that there is an exponential relationship between the temperature difference $\left(T-T_{\infty}\right)$ and the time $t$, where $T_{\infty}$ is the temperature of the cold water.

$$
\text { That is, }\left(\mathrm{T}-\mathrm{T}_{\infty}\right)=\mathrm{A} \mathrm{e}^{-\mathrm{Bt}}
$$

where $\mathrm{A}$ and $\mathrm{B}$ are constants

For our experimental run, the cold water temperature $\mathrm{T}_{\infty}$ was $57 \mathrm{~F}$. The response of the cylinder was as follows:

\begin{tabular}{|c|c|c|}
\hline Time $\mathrm{t}(\mathrm{s})$ & Temperature $\mathrm{T}(\mathrm{F})$ & $\underline{T-T_{\infty}}(\mathrm{F})$ \\
\hline 0 & 92.8 & $35 . \overline{8}$ \\
\hline 5 & 82.8 & 25.8 \\
\hline 10 & 80.0 & 23.0 \\
\hline 15 & 75.2 & 18.2 \\
\hline 20 & 70.8 & 13.8 \\
\hline 25 & 67.0 & 10.0 \\
\hline 30 & 65.5 & 8.5 \\
\hline
\end{tabular}

The students plotted $T$ - $T_{\infty}$ versus time on various types of graph axes and found that the data approximated a straight line when the $\mathrm{T}-\mathrm{T}_{\infty}$ axis was logarithmic and the time axis 
was linear. This meant that the data indeed followed an exponential relationship. The students used Matlab and the polyfit function to find the specific exponential relationship and then plotted the data and the function on the same graph.

The obtained function for the data was

$$
T-T_{\infty}=35.4284 e^{-0.0480 t}
$$

The graph is shown in Figure No. 6.

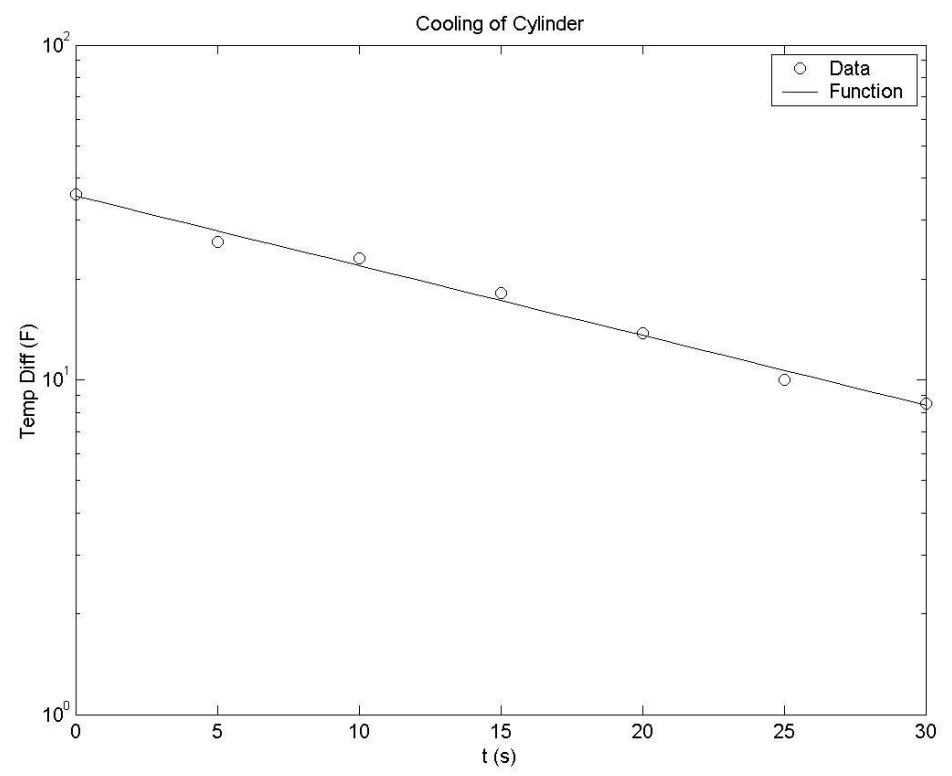

Figure No. 6 - Cooling of a Metal Cylinder

It is seen that the correlation between the data and the function is very good and that the function indeed plots as a straight line on linear-log axes.

\section{Deflection and Vibration of a Cantilever Beam Experiment}

Figure No. 7 shows the Cantilever Beam Experiment. A rectangular or round rod is attached at one end to a vibrator. This is the "fixed" end of the rod. The other end of the rod is unattached or "free". In addition to the rod, or "beam", the experimental apparatus includes the vibrator, the power supply for the vibrator, and a function generator to drive the vibrator ${ }^{9}$. 


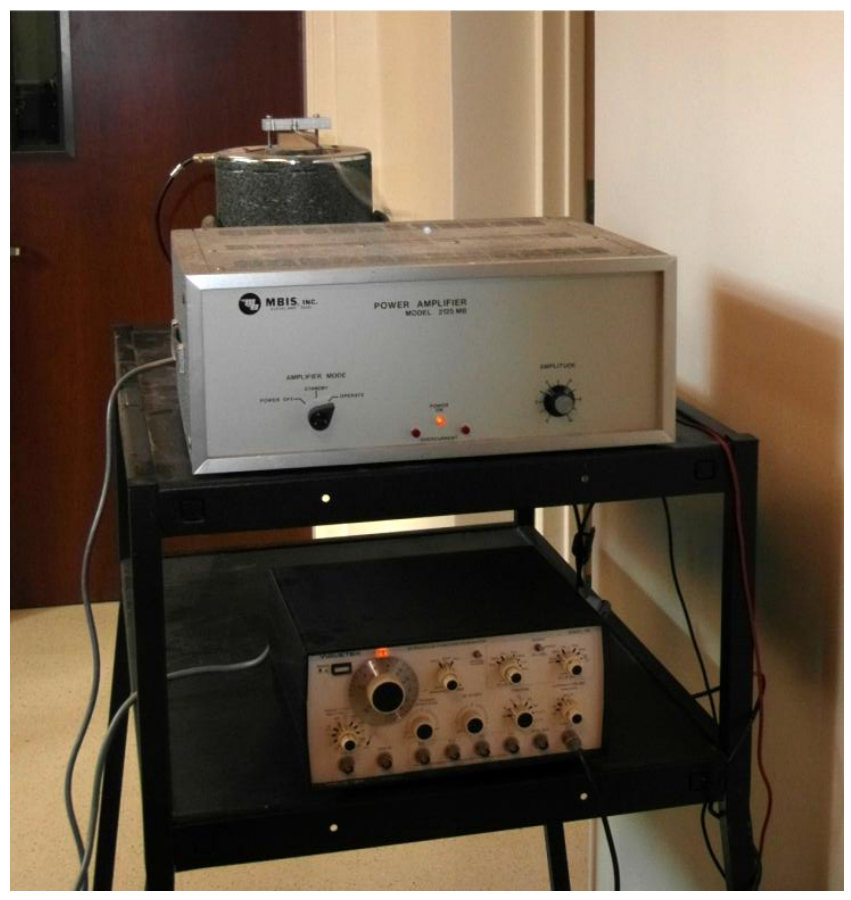

Figure No. 7 - The Cantilever Beam Experiment

If the vibrator is not in operation, weights can be hung from the free end of the rod and the deflection at the end measured for the different weights. The deflection of the free end is given by the equation ${ }^{10}$ :

$$
\delta=\frac{P L^{3}}{3 E I}
$$

where: $\delta=$ deflection of the free end of the beam

$\mathrm{P}=$ weight hung on the end

$\mathrm{L}=$ length of the beam

$\mathrm{E}=$ modulus of elasticity of the beam

$\mathrm{I}=$ moment of inertia of the cross section of the beam

It is seen that the deflection $\delta$ is directly proportional to the weight P. Students can perform the experiment, gather the $\delta$ versus $\mathrm{P}$ data, and determine the linear relationship between $\delta$ and $\mathrm{P}$ using the Matlab polyfit function.

A more-interesting experiment is when the vibrator is in operation and the fixed end of the beam is vibrating at a given frequency. It is found that there are certain frequencies (called "natural" frequencies) of vibration which cause natural modes of vibration. If the vibrator is off and the beam is deflected at the free end and released, the beam will vibrate at the first natural mode of vibration. If the vibrator is in operation at a frequency equal to the second natural frequency, the mode shape will have one location of zero displacement. Figure No. 8 shows the third natural mode of vibration of the beam. 


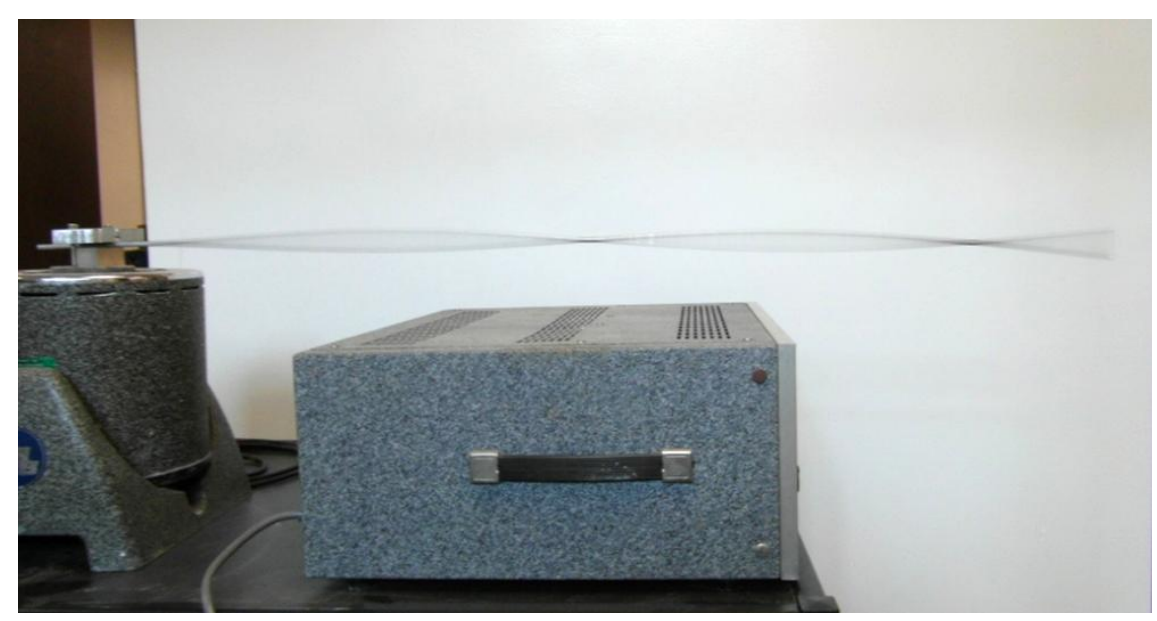

Figure No. 8 - The Third Mode of Vibration of the Cantilever Beam

Looking closely at the figure, it is seen that the beam has two nodal points of zero displacement. This occurs if the frequency of vibration is equal to the third natural frequency of the beam. The natural frequencies at which natural modes of vibration occur are obtained by solving the following equation for $\mathrm{A}_{\mathrm{n}}{ }^{11}$ :

$$
\cos \left(A_{n}\right) \cosh \left(A_{n}\right)=-1
$$

The students solve this equation using the Matlab fzero function. It turns out that there are six solutions of equation (5) in the range of $A_{n}=0$ to $A_{n}=20$. These are $A_{n}=1.875,4.694$, 7.855, 10.996, 14.137, and 17.279. Each solution is for a different natural frequency and a different mode shape. After the $A_{n}$ values are determined, the natural frequencies of the beam can be determined from ${ }^{12}$ :

$$
\omega_{n}=A_{n}^{2} \sqrt{\frac{E I}{\mu L^{4}}}
$$

The symbols not yet defined are $\quad \omega_{n}=$ frequency of the $n^{\text {th }}$ mode of vibration

$$
\mu \quad=\text { mass per unit length of the beam }
$$

From equation (6) it is seen that the natural frequencies of the beam are proportional to the square of the $A_{n}$ values.

Through experimentation, the natural frequencies of vibration for the first four modes of the rod shown in Figure No. 8 were found to be $4.3 \mathrm{~Hz}, 27 \mathrm{~Hz}, 73 \mathrm{~Hz}$ and $143 \mathrm{~Hz}$. Looking at the ratios 
of successive frequencies and using equation (6), it can be shown that these measured frequencies agree well with the theory, as follows:

$$
\begin{gathered}
\omega_{1} / \omega_{0}=\left(\mathrm{A}_{1} / \mathrm{A}_{0}\right)^{2}=(4.694 / 1.875)^{2}=6.267 \text { theoretical } \\
\omega_{1} / \omega_{0}=27 / 4.3=6.279 \text { measured } \\
\omega_{2} / \omega_{1}=\left(\mathrm{A}_{2} / \mathrm{A}_{1}\right)^{2}=(7.855 / 4.694)^{2}=2.800 \text { theoretical } \\
\omega_{2} / \omega_{1}=73 / 27=2.704 \text { measured } \\
\omega_{3} / \omega_{2}=\left(\mathrm{A}_{3} / \mathrm{A}_{2}\right)^{2}=(10.996 / 7.855)^{2}=1.960 \text { theoretical } \\
\omega_{3} / \omega_{2}=143 / 73=1.959 \text { measured }
\end{gathered}
$$

In short, the cantilever beam experiment can be used by students to curve-fit a linear function and also to determine the natural frequencies of vibration of the beam through solution of a nonlinear equation.

Student Survey on the Use of Experiments in the Computing Course

Experiments were used by the author in the freshman engineering computing course (ENGG 10) in the Spring 2011 and Fall 2012 semesters. A survey regarding the use of experiments was completed by all students on the last day of the course. A total of 64 students participated. The

\begin{tabular}{|c|c|c|c|c|}
\hline $\begin{array}{l}\text { Strongly } \\
\text { Disagree }\end{array}$ & Disagree & $\begin{array}{l}\text { Neither } \\
\text { Agree or } \\
\text { Disagree }\end{array}$ & Agree & $\begin{array}{l}\text { Strongly } \\
\text { Agree }\end{array}$ \\
\hline
\end{tabular}
survey and its detailed results are given below. The numbers below the categories indicate the number of students responding in the various categories.

Student Survey on the Use of Experiments in ENGG 10

Spring 2011 and Fall 2012 Semesters

\section{PLEASE TELL ME HOW YOU FEEL}

I enjoyed the use of experiments in techniques. 
The experiments increased the student participation in the class.

Experiments should not be used in

the course.

The experiments took too much class time. 15

29

16

4

0

I would recommend that more experiments

1

$\begin{array}{lll}2 & 12 & 30\end{array}$

19

be added to the course.

I would recommend that experiments

$1 \quad 1$

10

32

20

be incorporated in other lecture courses.

\section{OVERALL REACTIONS}

How would you rate the use of experiments in this computing course ?

Poor Fair Good Excellent

$\begin{array}{llll}4 & 16 & 33 & 11\end{array}$

How would you change or improve the use of experiments in this course ?

A sampling of typical student comments:

"I think that more experiments should be used because it encourages student participation a lot more and it makes the problems easier to understand."

"Base the experiments on topics the students are likely to already know. Using a thermodynamics problem leads students to be unsure if their confusion stems from Matlab problems or just not knowing thermodynamics."

"There should be more experiments because the problems we do in Matlab apply to so many other courses like heat transfer and circuits, and I think experiments would give the students a better foundation and understanding for the future."

"I would have experiments used more frequently because some students may not see the importance of using Matlab. But with experiments the students will see it is important to make calculations with Matlab."

"All experiments were very self-explanatory and useful in the class."

"I would encourage more class participation and more explanation of the experiments before performing them."

"I think there should be more experiments so we can see what the numbers on the screen actually mean in real life." 
"I would add more experiments. There are many different uses for Matlab and actually witnessing them makes it much easier to understand."

"Add more experiments. This allows students to see how the program will be used in their engineering career."

"Maybe you could designate a certain period of time within the class meeting to experiments and hold one once a week or once every other week."

"The use of experiments is good. It gives students a visual instead of watching a computer screen. The only way to improve experiment use is to add more!"

"Use more experiments. Helps me to understand the concepts."

"Some students can either be hands-on or visual learners. Use of experiments increases student interaction as well as the understanding of the material because there is physical proof of what may go on in a problem, instead of just taking it from a textbook and accepting it."

"I think experiments are good for the course because they add variety to class time and activities, and students can get more involved."

"The experiments are fine. They should be more interactive."

"I think the experiments added a good dynamic to the course and gave us a challenge. I thoroughly enjoyed the experiments incorporated in the class."

And a final gem: "Make the experiments more exciting. Maybe ones that are more loud and have brighter colors. We engineers are usually half asleep as it is from studying all night."

Summarizing: The majority of the students were very favorable to the use of experiments in the course. They enjoyed the experiments and thought that they significantly contributed to the students' understanding of Matlab and the usefulness of Matlab in solving engineering problems. Many students recommended that additional experiments be incorporated in the course. It is noted that 4 of the 64 students gave a "poor" rating to the use of experiments in the course. The reason for this low rating is unknown, but, in any case, only a very small minority of the students felt this way.

Planned Future Work

Three of the four described experiments (i. e., the electric circuit, the cooling of a cylinder, and the cantilever beam experiments) are portable and can be moved via carts into the computer lab. Plans are to make a small-scale, portable version of the orifice flow meter experiment that can also be transported into the computer lab. It is also planned to modify the experiments so that experimental results can be projected in real-time on the computer lab screen.

\section{Conclusions}

This paper discusses experiments which have been added to the freshman engineering computing course at Hofstra University. This inclusion of experiments could be readily implemented at 
other universities to make the course more appealing to, and enjoyable for, the students. The addition of experiments has been very well-received by the students. It has enhanced the dynamics of class sessions through increased student participation, and it is believed that the use of experiments has resulted in a very positive impact on student motivation. The author believes that the use of experiments has improved the students' understanding of the course material. However, due to lack of a control group, this belief cannot be confirmed by the current study.

\section{Bibliography}

1. B. Ferri and J. Auerbach, Work in Progress - A Program to Incorporate Portable Labs Into LectureBased Electrical and Computer Engineering Courses, 40th ASEE/IEEE Frontiers in Education Conference, October 27 - 30, 2010, Washington, DC.

2. A. Niemi, In-Class Circuits: Using Passive Components to Create Active Learning, Proceedings of the 2008 ASEE Annual Conference, June 22-25, 2008, Pittsburgh, PA.

3. C. H. Forsberg, A Demonstration Unit to Enhance Heat Transfer Lectures on Natural and Forced Convection, Proceedings of the 2003 ASEE Annual Conference, June 22-25, 2003, Nashville, TN.

4. A. Gilat, Matlab - An Introduction with Applications, 4th edition, Wiley, 2011. Page 94, Problem 34.

5. Cen-Tech Digital Multimeter (Item 98025)

6. TecQuipment, Inc., Flow Measuring Devices Experiment

7. Omega Engineering, Thermometer HH66U

8. F. Kreith, R. M. Manglik, and M. S. Bohn, Principles of Heat Transfer, 7th edition, Cengage Learning, 2011. Page 118, Equation (2.89).

9. MBIS, Inc. vibrator; MBIS, Inc. Model $2125 \mathrm{MB}$ power amplifier; Wavetek $20 \mathrm{MHz}$ pulse / function generator

10. S. Timoshenko and D. H. Young, Elements of Strength of Materials, 4th edition, Van Nostrand, 1962. Page 212.

11. F. S. Tse, I. E. Morse, R. T. Hinkle, Mechanical Vibrations - Theory and Applications, 2nd edition, Allyn and Bacon, 1978. Pages 277 and 278.

12. J. P. Den Hartog, Mechanical Vibrations, McGraw-Hill, 1956, Page 432. 